\title{
Nitric Oxide Plays an Important Role in $\beta$-Aminobutyric Acid-Induced Resistance to Botrytis cinerea in Tomato Plants
}

\author{
Rui Li ${ }^{1}$, Jiping Sheng ${ }^{2}$, and Lin Shen (iD) ${ }^{1 *}$ \\ ${ }^{1}$ College of Food Science and Nutritional Engineering, China Agricultural University, Beijing 100083, China \\ ${ }^{2}$ School of Agricultural Economics and Rural Development, Renmin University of China, Beijing 100872, China
}

(Received on November 13, 2019; Revised on February 16, 2020; Accepted on March 3, 2020)

$\beta$-Aminobutyric acid (BABA) has consistently been reported to enhance plant immunity. However, the specific mechanisms and downstream components that mediate this resistance are not yet agreed upon. Nitric oxide (NO) is an important signal molecule involved in a diverse range of physiological processes, and whether NO is involved in BABA-induced resistance is interesting. In this study, treatment with BABA significantly increased NO accumulation and reduced the sensitivity to Botrytis cinerea in tomato plants. BABA treatment reduced physical signs of infection and increased both the transcription of key defense marker genes and the activity of defensive enzymes. Interestingly, compared to treatment with $\mathrm{BABA}$ alone, treatment with $\mathrm{BABA}$ plus cPTIO (NO specific scavenger) not only significantly reduced NO accumulation, but also increased disease incidence and lesion area. These results suggest that NO accumulation plays an important role in BABA-induced resistance against $B$. cinerea in tomato plants.

Keywords : $\beta$-aminobutyric acid, Botrytis cinerea, nitric oxide, tomato plants

Handling Editor : Jeum Kyu Hong

*Corresponding author.

Phone) +86-10-62737620, FAX) +86-10-62737620

E-mail)shen5000@cau.edu.cn

ORCID

Lin Shen

https://orcid.org/0000-0002-3942-4367

(c) This is an Open Access article distributed under the terms of the Creative Commons Attribution Non-Commercial License (http:// creativecommons.org/licenses/by-nc/4.0) which permits unrestricted noncommercial use, distribution, and reproduction in any medium, provided the original work is properly cited.

Articles can be freely viewed online at www.ppjonline.org.
Tomato (Solanum lycopersicum. L) is the world's fourth most economically important crop because of its great nutritional and commercial values (Zhu et al., 2018). Botrytis cinerea is a netrotrophic pathogen that leads to devastating plant diseases, which result in significant economic losses worldwide. A variety of fruits and vegetables including greenhouse-grown tomatoes are affected by $B$. cinerea (Zheng et al., 2015).

Plant defense priming was first noted in 1933 and initially termed 'sensitization' (Chester, 1933), and it was accepted to be the pivotal phenomenon in systemic plant immunity (Conrath, 2011). Priming is widely understood to be activated by exposure to a priming agent, often a pathogen. Even if this initial contact does not lead to a defense response or virulent interaction, we expect to see the defense responses deployed in a faster, stronger, and/or more sustained manner following a subsequent triggering pathogen attack (Conrath, 2011; Wang et al., 2018). In effect, initial exposure to a priming agent leads to enhanced resistance to later pathogen attacks. Previous studies showed that some elicitors such as methyl jasmonate (MeJA) (Saavedra et al., 2017), Bacillus cereus AR156 (Wang et al., 2013), and the nonprotein amino acid $\beta$-aminobutyric acid (BABA) (Thevenet et al., 2017; Worrall et al., 2012) could prime disease resistance.

BABA has been investigated as a potential chemical inducer of disease resistance for more than 50 years (Cohen et al., 2016; Thevenet et al., 2017). Previous reports have showed that BABA could enhance plant resistance to pathogens and the efficiency of BABA treatment was associated with the specific plant-pathogen interaction (Flors et al., 2008; Floryszak-Wieczorek et al., 2012). Studies in Arabidopsis reported that BABA treatment conferred enhanced resistance against infections caused by $P s t$ DC3000, Hyaloperonospora arabidopsidis, and Plectosphaerella cucumerina (Ji et al., 2015; Ton and Mauch- 
Mani, 2004; Ton et al., 2005). Some important crop plants such as potato (Floryszak-Wieczorek et al., 2015), bean (Martínez-Aguilar et al., 2016), and tomato (Worrall et al., 2012) have been successfully protected by BABA. Additionally, BABA-induced resistance was found to enhance basal defense responses such as lignin formation, callose deposition and reactive oxygen species accumulation in many species (Ji et al., 2015; Ton and Mauch-Mani, 2004). However, studies in tobacco showed that BABA-induced resistance against Peronospora tabacina depends on the salicylic acid (SA) signaling pathway, and treated plants do not show enhanced lignin formation or callose deposition (Cohen, 2002).

Nitric oxide (NO) is a highly diffusible gas and a ubiquitous bioactive molecule (Sami et al., 2018). NO synthesis is accomplished by a family of nitric oxide synthase (NOS) enzymes as well as several other enzymes, and all of which have been well researched in mammals (Zheng et al., 2011). However, the NO synthesis gene in tomato has not been identified until now (Del Río et al., 2004; Zhang et al., 2011). Interestingly, the identified NOS gene and protein sequences in Arabidopsis and tobacco show no sequence similarities to the NOS family of enzymes in animals (Del Río et al., 2004), which brings into the question whether the identified NOS genes or their homologous genes really encode NOS enzymes in all plant species (Crawford, 2006). Due to the lack of NOS synthesis mutants in many plant species, NO's donor and scavenger were widely used to study the function of NO in plants (Wany et al., 2017; Zheng et al., 2014).

Recently, increasing evidence demonstrated $\mathrm{NO}$ as a potential mediator involved in plant resistance against various pathogens (Fan et al., 2008; Floryszak-Wieczorek et al., 2012; Gill et al., 2013). Previous studies showed that an early transient NO burst is an important signal required for plant resistance against necrotrophic fungal pathogens, such as B. cinerea or Sclerotinia sclerotiorum (Arasimowicz-Jelonek and Floryszak-Wieczorek, 2016; Perchepied et al., 2010). The interaction between Solanum spp. and Oidium neolycopersici had also confirmed the positive role of NO in defense activation (Piterková et al., 2011). Additionally, application of sodium nitroprusside (a NO donor) treatment enhanced resistance against $B$. cinerea in tomato fruit (Zheng et al., 2014), and protected tomato plants against Rhizoctonia solani infection through activating the cell wall-associated defense response (Noorbakhsh and Taheri, 2016). In potato, BABA-triggered priming involves NO generation and reversible S-nitrosylated protein storage (Floryszak-Wieczorek et al., 2012). However, little information is available about the special role of NO in BABA- mediated resistance.

The objectives of this study are to (1) investigate the effect of BABA treatment on tomato plants infected by $\mathrm{B}$. $\mathrm{ci}$ nerea and (2) study the special role of NO in BABA-mediated resistance against $B$. cinerea. Tomato plants from the 'Ailsa Craig' background were used to evaluate BABAmediated resistance by monitoring disease incidence, lesion area, defense enzyme activity, defense gene expression and plant hormone level after $B$. cinerea inoculation.

\section{Materials and Methods}

Plant materials and pathogen. 'Ailsa Craig' (AC) tomato (Solanum lycopersicum) plants were planted in plastic pots (7 cm diameter) containing substrate/vermiculite/black soil $(2: 1: 1, \mathrm{v} / \mathrm{v} / \mathrm{v})$ and grown in a standard greenhouse (25 $\pm 2^{\circ} \mathrm{C}, 65-70 \%$ relative humidity $[\mathrm{RH}]$ and photoperiod of $16 \mathrm{~h}$ light $/ 8 \mathrm{~h}$ dark). AC seeds were kindly provided by Dr. Jim Giovannoni (Boyce Thompson Institute for Plant Research, Ithaca, NY, USA). Six-week-old tomato plants were used for further experiments.

B. cinerea (ACCC no. 36028) used in our study was purchased from the Agricultural Culture Collection of China (Haidian, Beijing) and were cultured on PDA medium at $22 \pm 2^{\circ} \mathrm{C}$ for 10 days to induce sporangium formation.

Treatments and inoculation. Treatments were performed following the methods described by Bengtsson et al. (2014). Six-week-old tomato plants were sprayed with (1) water (as control), (2) $1 \mathrm{mM}$ BABA (purity $\geq 98 \%$, Macklin, Shanghai, China), (3) $0.2 \mathrm{mM}$ cPTIO (purity $\geq 98 \%$, Sigma, St. Louis, MO, USA), and (4) $1 \mathrm{mM} \mathrm{BABA}$ plus $0.2 \mathrm{mM} \mathrm{cP-}$ $\mathrm{TIO}$, and then these plants were transferred to a chamber at $25 \pm 2{ }^{\circ} \mathrm{C}$ with $16 / 8 \mathrm{~h} \mathrm{light/dark} \mathrm{photoperiod.} \mathrm{The} \mathrm{fourth} \mathrm{to}$ sixth unfolded leaves from stem base were collected after spraying treatment (time 0 ), at 2, 4, 6, 12, and $24 \mathrm{~h}$, frozen quickly in liquid nitrogen, and stored at $-80^{\circ} \mathrm{C}$ for analyzing NO level.

Pathogen inoculation was carried out after spraying for 2 days according to Audenaert et al. (2002) Spores were suspended with sterile distilled water, and inoculum droplets (10 $\mu$ l containing $1 \times 10^{4}$ spores) were put on surfaces of the fourth to sixth unfolded leaves from stem base. Inoculated plants were kept at $100 \% \mathrm{RH}$ and $22 \pm 2^{\circ} \mathrm{C}$ for $24 \mathrm{~h}$, and then returned to a growth cabinet maintained at $25 \pm$ $2^{\circ} \mathrm{C}$ with $16 \mathrm{~h}$ light $/ 8 \mathrm{~h}$ dark per day. The inoculated leaflets were sampled after $B$. cinerea inoculation (time 0 ), at 4 , $16,24,48$, and $72 \mathrm{~h}$, stored at $-80^{\circ} \mathrm{C}$ until measurement of defense enzymes activities and defense genes expressions. Additionally, 10 tomato plants of each group were used for 
measuring disease symptom on 2 and 4 days after inoculation. Three plants were used for sampling at every time point. Every experiment was carried out with three biological repeats.

Disease symptom measurement. The severity of disease symptom was monitored by measuring disease incidence and lesion diameter. Disease incidence was evaluated based on the proportion of infected leaves exhibiting disease symptom. Lesion area reflected the size occupied by gray lesions of leaves infected with $B$. cinerea, and was measured by $3.14 \times(\text { lesion diameter } / 2)^{2}$. Three biological replicates were carried out in this experiment.

RNA isolation and quantitative reverse transcription PCR (RT-qPCR). Total RNA was isolated from frozen leaf tissue with an EasyPure Plant RNA Kit (Transgene, Beijing, China) according to the manufacturer's protocol. RNA integrity was evaluated with $2 \%$ agarose gel electrophoresis, and quantified with a micro spectrophotometry (NanoDrop 2000, Thermo Scientific, Waltham, MA, USA) under non-denaturing conditions. Then $2 \mu \mathrm{g}$ total RNA was used for the first-strand cDNA synthesis with a TransScript One-Step gDNA Removal and cDNA Synthesis SuperMix Kit (Transgene). Next, qRT-PCR was carried out with TransStart Top Green qPCR SuperMix (Beijing Transgen Biotech Co. Ltd., Beijing, China) using the BIO-RAD qPCR system (CFX96, Bio-Rad, Hercules, CA, USA). The thermocycling program was as follows: $95^{\circ} \mathrm{C}$ for $3 \mathrm{~min}$, followed by 40 cycles of $95^{\circ} \mathrm{C}$ for $15 \mathrm{~s}$, and $60^{\circ} \mathrm{C}$ for $30 \mathrm{~s}$. Fluorescence changes were monitored in each cycle and $\beta$-Actin was used as the internal control for normalization. The relative expression levels were calculated following the $2^{-\Delta \Delta C t}$ method (Livak and Schmittgen, 2001). Every experiment included three biological repeats. Sequences of specific primers used for qRT-PCR are listed in Table 1.

Measure of NO accumulation. NO was metabolized to nitrite $\left(\mathrm{NO}_{2}^{-}\right)$and nitrate $\left(\mathrm{NO}_{3}^{-}\right)$under acid conditions in vivo, and quantitation of these stable anions with Griess reagent was used to indirectly determine NO content. Extracts for NO were carried out on the base of the methods reported by Hao et al. (2008) with some modifications. Frozen tissue in powder $(0.4 \mathrm{~g})$ was vigorously mixed with $5 \mathrm{ml}$ of cold $50 \mathrm{mM}$ phosphate buffer sodium (PBS) ( $\mathrm{pH}$ 7.4, which contained $1 \mathrm{mM}$ dithiothreitol, $1 \mathrm{mM} \mathrm{MgCl}$ ) with the T10 basic Disperser (IKA, Darmstadt, Germany) and centrifuged at $12,000 \times g$ for $20 \mathrm{~min}$ at $4^{\circ} \mathrm{C}$. The supernatant was collected for the measurement of $\mathrm{NO}$ content using NO assay kits (Jiancheng, Nanjing, China) according to the operation instructions and the absorbance was measured at $550 \mathrm{~nm}$. The release of NO in the plant tissue was expressed as nitrite concentration, which was defined from a plotted standard curve. NO content was expressed as $\mu \mathrm{mol} / \mathrm{g}$ fresh weight (FW).

Assay for defense enzymes. Activities of phenylalanine ammonialyase (PAL, EC 4.3.1.5), polyphenol oxidase (PPO, EC 1.10.3.2), $\beta$-1,3-glucanases (GLU, EC 3.2.1.39), and chitinase (CHI, EC 3.2.1.14) were analyzed as representatives of defense enzymes. Activities of PAL, PPO, GLU, and CHI were measured following the methods described by our previous report (Zheng et al., 2014). One unit of PAL activity was defined as the amount of enzyme causing an increase in absorbance of 1 at $290 \mathrm{~nm}$ per hour. One unit of PPO activity was defined as the amount of enzyme causing a change of 1 in absorbance per minute. One unit of GLU activity was defined as the formation of $1 \mu \mathrm{mol}$ of glucose per hour. One unit of CHI activity was defined as the amount of $10^{-9} \mathrm{~mol} \mathrm{~N}$-acetyl-D-glucosamine being produced per hour. These defense enzymes activities were expressed as $\mathrm{U} / \mathrm{g}$ FW.

Assay for plant hormone concentrations. To determine the concentrations of indole acetic acid (IAA), abscisic acid (ABA), gibberellic acid $\left(\mathrm{GA}_{3}\right)$, and MeJA, a simplified indirect competitive enzyme-linked immunosorbent assay was used (Deng et al., 2008). Frozen tissue in powder $(0.2$ g) was extracted and homogenized with $2 \mathrm{ml}$ of extraction buffer $(80 \%$ methanol, containing $40 \mathrm{mg} / \mathrm{l}$ butylated

Table 1. Sequences of specific primers used for qRT-PCR analysis

\begin{tabular}{llll}
\hline Name & Accession no. & Forward primer $\left(5^{\prime} \rightarrow 3^{\prime}\right)$ & Reverse primer $\left(5^{\prime} \rightarrow 3^{\prime}\right)$ \\
\hline$\beta$-actin & NM_001308447 & CAGCAGATGTGGATCTCAAA & CTGTGGACAATGGAAGGAC \\
SlPR1 & NM_00124735 & TCATTCTGGTGCTGGGGAG & CACATTGGTTGGTAGCGTAGTT \\
SINPR1 & NM_00124769 & CATAACCCTTGATAAGTCCT & CCAATGCTCTATGTATCCTC \\
SIEDS1 & NM_00132029 & GGAATTGAAGTCAGAGATGAGCTAA & AAAGTTCCAGCAAAAGCAAAAA \\
SlFAD4 & XM_01921210 & CCGTGATCAGATGGTAGAAATAATG & CGGCAGAGAAGCCAGAGAGT \\
\hline
\end{tabular}

qRT-PCR, quantitative reverse transcription polymerase chain reaction. 
hydroxytoluene as an antioxidant) using an IKA disperser. The extract was incubated at $4^{\circ} \mathrm{C}$ for $48 \mathrm{~h}$, and centrifuged at $12,000 \times \mathrm{g}$ for $15 \mathrm{~min}$ at $4^{\circ} \mathrm{C}$. Then, the supernatant was collected and passed through a C18-SepPak classic cartridge (Waters, Milford, CT, USA). The residue was eluted with $10 \mathrm{ml}$ of $100 \%$ (v/v) methanol and then $10 \mathrm{ml}$ of ether. Finally, the eluate was dried by pure nitrogen at $20^{\circ} \mathrm{C}$, and dissolved with $2 \mathrm{ml} \mathrm{PBS} \mathrm{(0.1} \mathrm{mM} \mathrm{pH} \mathrm{7.5,} \mathrm{containing} \mathrm{1 \%} \mathrm{(v/}$ v) Tween-20 and $0.1 \%(\mathrm{w} / \mathrm{v})$ gelatin) to quantify hormone concentrations. The contents of phytohormone were expressed as $\mathrm{ng} / \mathrm{g} \mathrm{FW}$.

Statistical analysis. Statistical analysis was carried out via one-way analysis of variance (ANOVA) and Duncan's multiple range tests using the SPSS version 19.0 (IBM Corp., Armonk, NY, USA) software, and differences were considered significant if $P<0.05$.

\section{Results}

Effects of BABA treatment on tomato plant resistance against $B$. cinerea. To estimate the effects of BABA on tomato plant resistance against $B$. cinerea, we carried out the preliminary experiment by spraying BABA at concentrations of $0.1,0.5,1.0,3.0$, and $5.0 \mathrm{mM}$ (water as control). Results showed that leaves treated with BABA at concentrations of $0.1,0.5$ and $1 \mathrm{mM}$ showed no visible necrosis during the whole sampling period (Fig. 1A-D). However, the leaves of tomato plants treated by 3- or 5-mM BABA exhibited serious necrosis and even shrank from the second day after treatment (Fig. 1E and F). Furthermore, on 2 and 4 days after $B$. cinerea inoculation, the disease incidences of plants treated with $1 \mathrm{mM}$ BABA significantly decreased by $16.9 \%$ and $20.4 \%$ compared to control, respectively ( $P$ $<0.05$ ) (Fig. 2A and B). The lesion areas of plants treated with $1 \mathrm{mM}$ BABA decreased by $75.9 \%$ and $81.5 \%$ on 2 and 4 days after $B$. cinerea inoculation compared to control, respectively $(P<0.05)$ (Fig. $2 C)$. These data show that the effectiveness of BABA at protecting tomato plants from $B$. cinerea is closely associated with its application concentration, and $1 \mathrm{mM} \mathrm{BABA}$ treatment is used for further experiments. These results also confirm the previous reports about the role of BABA in enhancing plant immunity.

Effects of BABA treatment on defense enzymes activities. In order to better understand the nature of BABAinduced resistance, we examined the activity of four defense enzymes in response to BABA treatment and $B$. cinerea inoculation. Compared with control, BABA treatment significantly increased PAL activity at $4,16,24$, and $72 \mathrm{~h}$ after inoculation $(P<0.05)$ (Fig. 3A). GLU activity in BABA-treated plants was remarkably higher than that in the control, and it peaked at $4 \mathrm{~h}$ after inoculation with 75.7 $\mathrm{U} / \mathrm{g} \mathrm{FW}(P<0.05)$ (Fig. 3B). After $B$. cinerea inoculation, PPO activities in BABA-treated plants and control plants
A
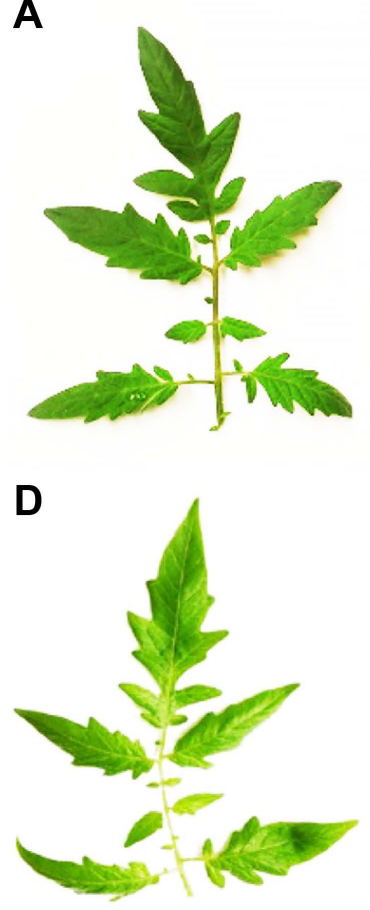
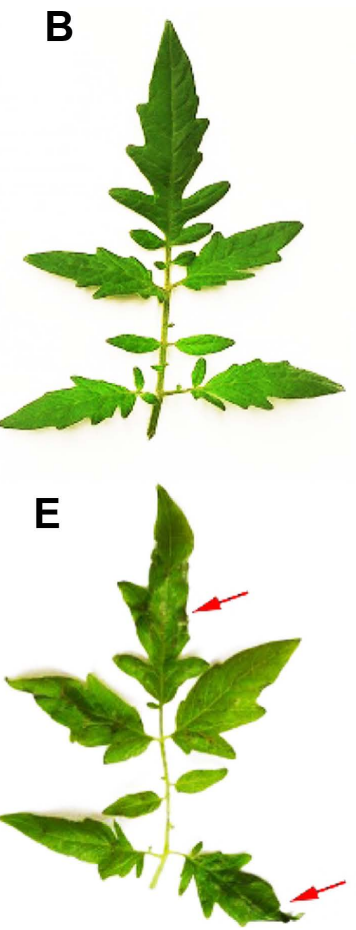
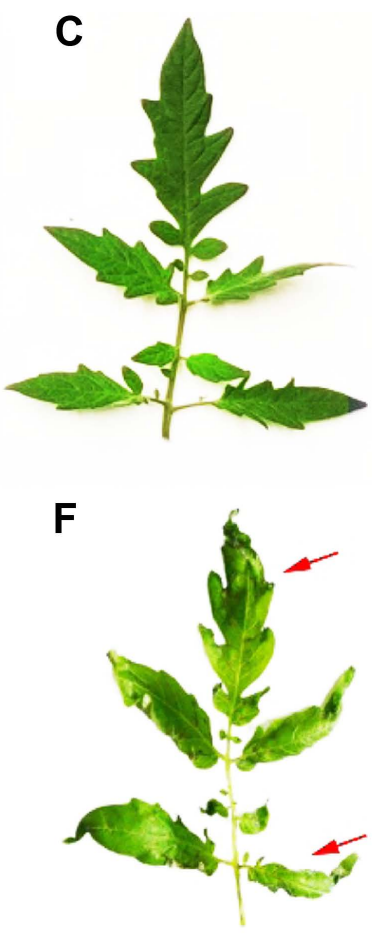

Fig. 1. Phenotypes of tomato leaves treated with water (A), $0.1 \mathrm{mM}(\mathrm{B}), 0.5$ $\mathrm{mM}(\mathrm{C}), 1 \mathrm{mM} \beta$-aminobutyric acid (BABA) (D), $3 \mathrm{mM}$ BABA (E), and 5 mM BABA (F). The pictures were taken on 2 days after treatment. 

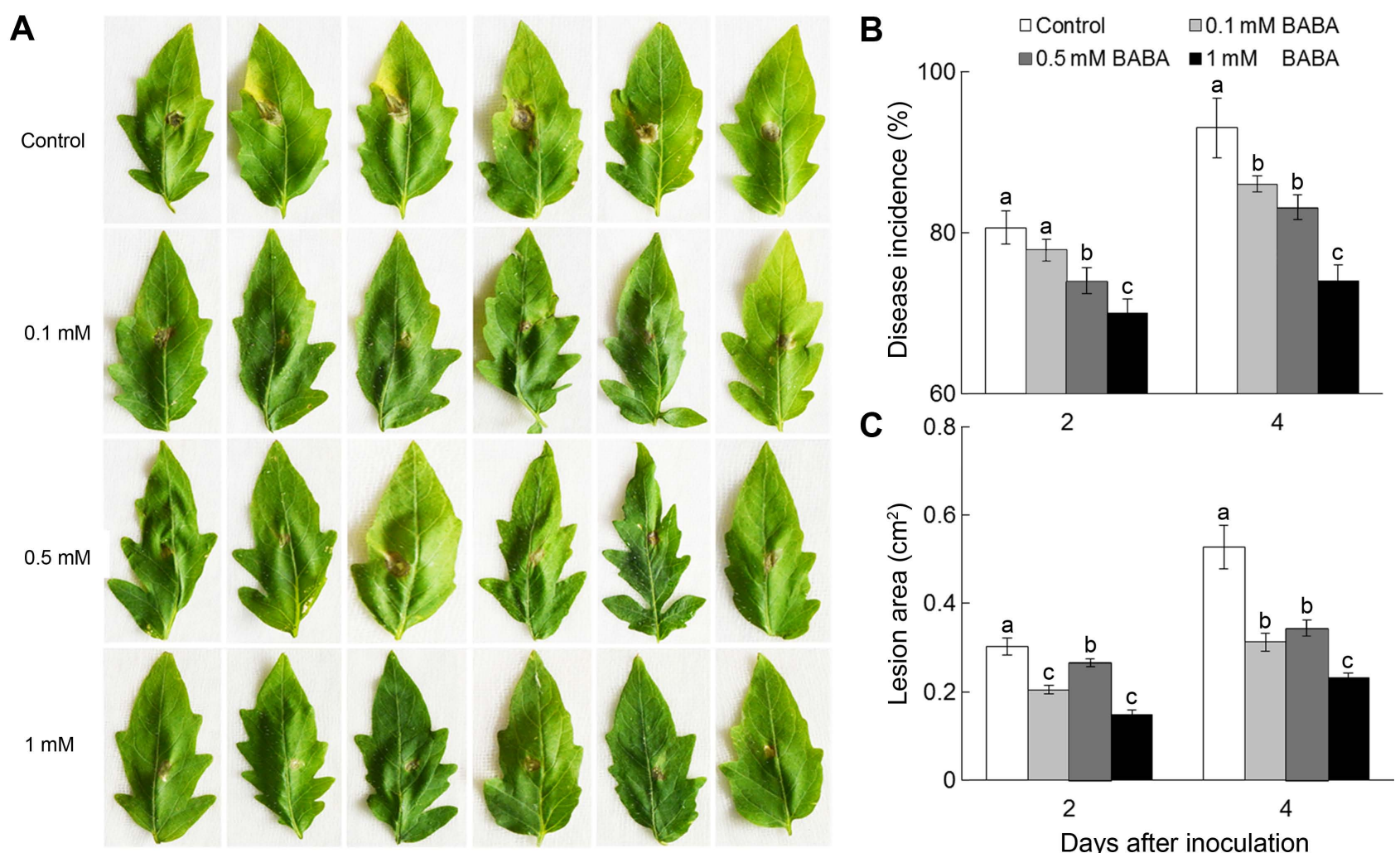

Fig. 2. Effects of treatment with different concentrations of $\beta$-aminobutyric acid (BABA) on the disease phenotype (A), disease incidence (B), and lesion area (C). The leaves were imaged 4 days after inoculation with Botrytis cinerea. Disease incidence and lesion area were recorded during the incubation for 2 and 4 days at $25^{\circ} \mathrm{C}$. Values followed by different letters are significantly different according to Duncan's multiple range tests at $P<0.05$. Data are expressed as mean $\pm \mathrm{SD}$ of triplicate assays.

all exhibited a continuous increase. However, PPO activity in control plants was consistently lower than that in BABAtreated plants during the whole sampling period $(P<0.05)$ (Fig. 3C). Moreover, plants treated with BABA exhibited a significant increase in CHI activity, which peaked at $24 \mathrm{~h}$ with $15.8 \mathrm{U} / \mathrm{g} \mathrm{FW}(P<0.05)$ (Fig. 3D).

Effects of BABA treatment on expression of defense genes. In order to further investigate the specific mechanisms of BABA-induced resistance, we examined the expression of defense mark genes in response to BABA treatment and $B$. cinerea inoculation. BABA treatment also significantly enhanced the relative expression of four defense marker genes: SlPR1, SlNPR1, SlEDS1, and SlFAD4 $(P<0.05)$ (Fig. 4). After B. cinerea inoculation, plants treated by BABA immediately showed a significant increase in SIPR1 and SIEDS1 transcription. SIPR1 transcription in BABA-treated plants was 21.25-, 14.21-, 3.88-, 4.48-, 2.84-, and 3.32-fold higher than that in control at 0,4 , $16,24,48$, and $72 \mathrm{~h}$ post inoculation, respectively $(P<0.05)$ (Fig. 4A). Moreover, relative expression of SIEDS1 in BA-
BA-treated plants was similar to SIPR1, which was 3.18-, 2.11-, 4.36-, 1.80-, 1.71-, and 2.56-fold higher compared to control at $0,4,16,24,48$, and $72 \mathrm{~h}$, respectively $(P<0.05)$ (Fig. 4B). The transcript levels of SINPR1 and SIFAD4 in BABA-treated plants remained higher after inoculation, and the values were 2.87 and 6.33 times that in control at 16 h, respectively $(P<0.05)$ (Fig. 4C and D).

Effects of BABA treatment on the levels of plant hormones. To investigate the role of plant hormones in BABA-induced resistance, the concentrations of IAA, ABA, $\mathrm{GA}_{3}$, and MeJA were measured. IAA concentration in BABA-treated plants was significantly higher than control and it continuously increased at $4 \mathrm{~h}$ after inoculation $(P<0.05)$ (Fig. 5A). ABA content in BABA-treated plants showed a significant decrease at $4 \mathrm{~h}$ after inoculation $(P<0.05)$ (Fig. 5B). However, ABA concentration in control plants remained almost unchanged. Furthermore, concentration in BABA-treated plants increased rapidly after inoculation, rising above control levels at $24 \mathrm{~h}$ post inoculation and peaking at $48 \mathrm{~h}$ with a maximum value of $8.11 \mathrm{ng} / \mathrm{g} \mathrm{FW}$ 
A

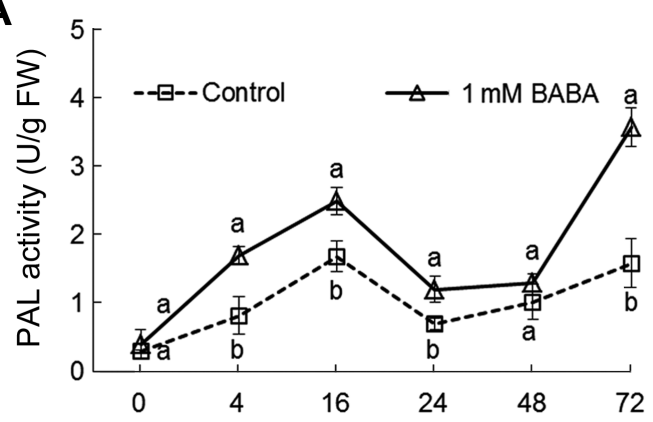

C

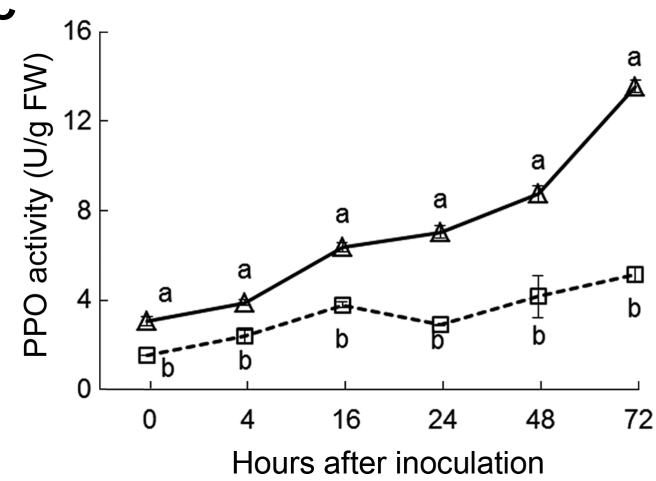

B

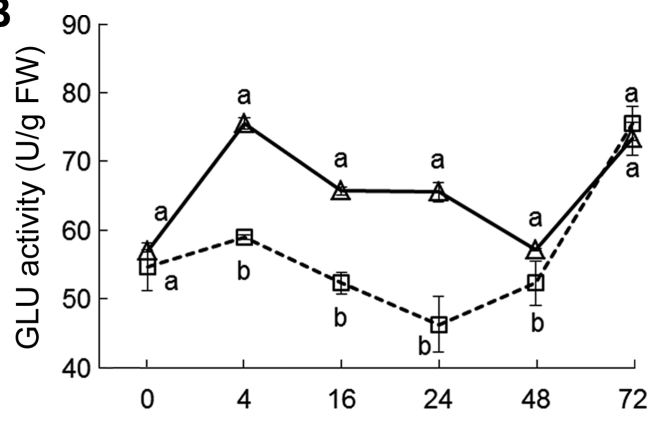

D

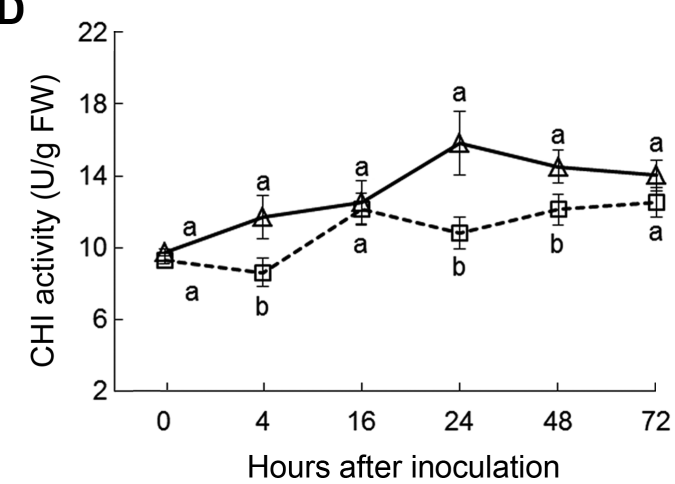

Fig. 3. Effects of $\beta$-aminobutyric acid (BABA) treatment on activities of phenylalanine ammonialyase (PAL) (A), $\beta$-1,3-glucanases (GLU) (B), polyphenol oxidase (PPO) (C), and Chitinase (CHI) (D). Values followed by different letters are significantly different according to Duncan's multiple range tests at $P<0.05$. Data are expressed as mean $\pm \mathrm{SD}$ of triplicate assays.
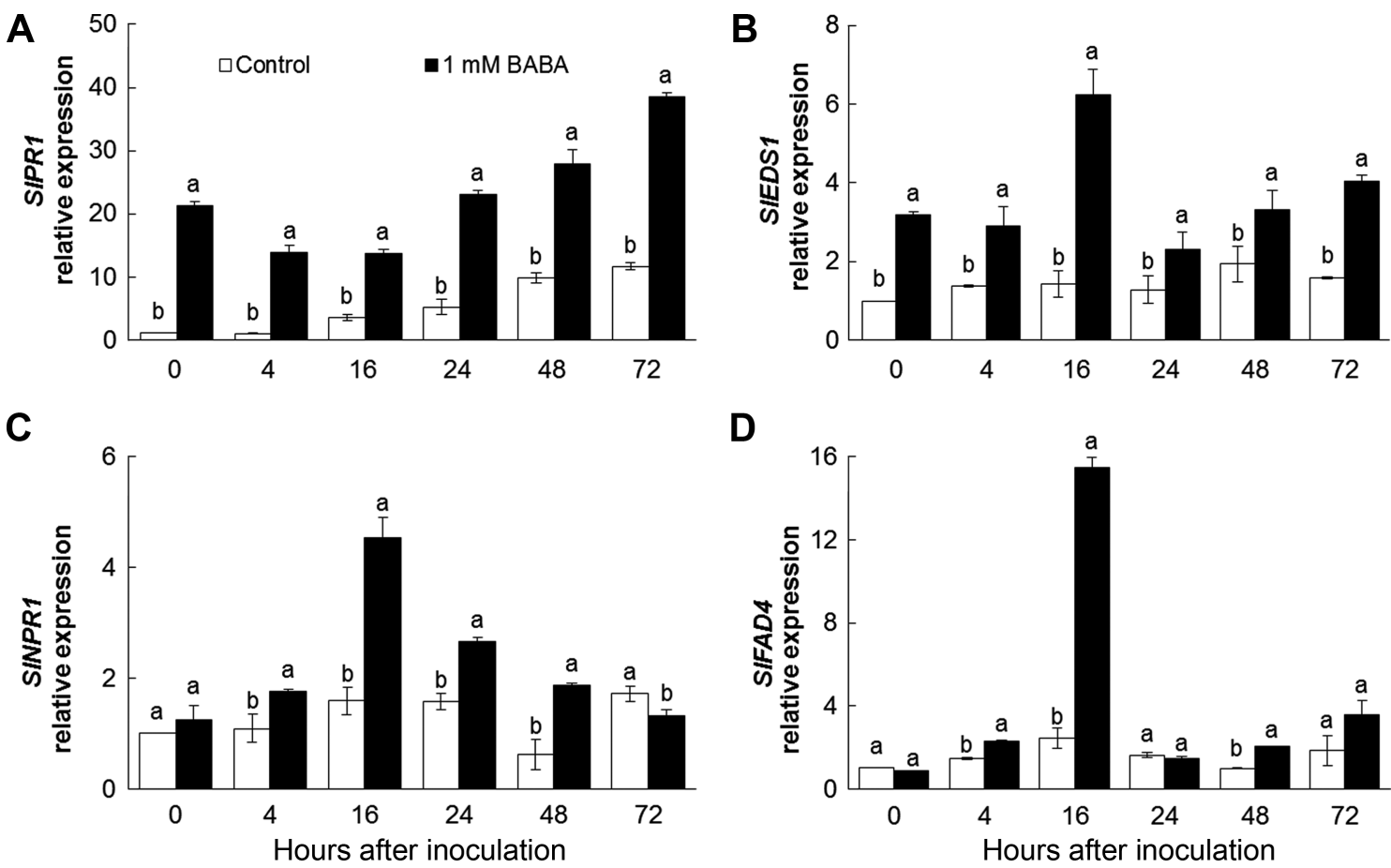

Fig. 4. Effects of $\beta$-aminobutyric acid (BABA) treatment on relative expressions of SIPR1 (A), SIEDS1 (B), SINPR1 (C), and SIFAD4 (D). Values followed by different letters are significantly different according to Duncan's multiple range tests at $P<0.05$. Data are expressed as mean \pm SD of triplicate assays. 

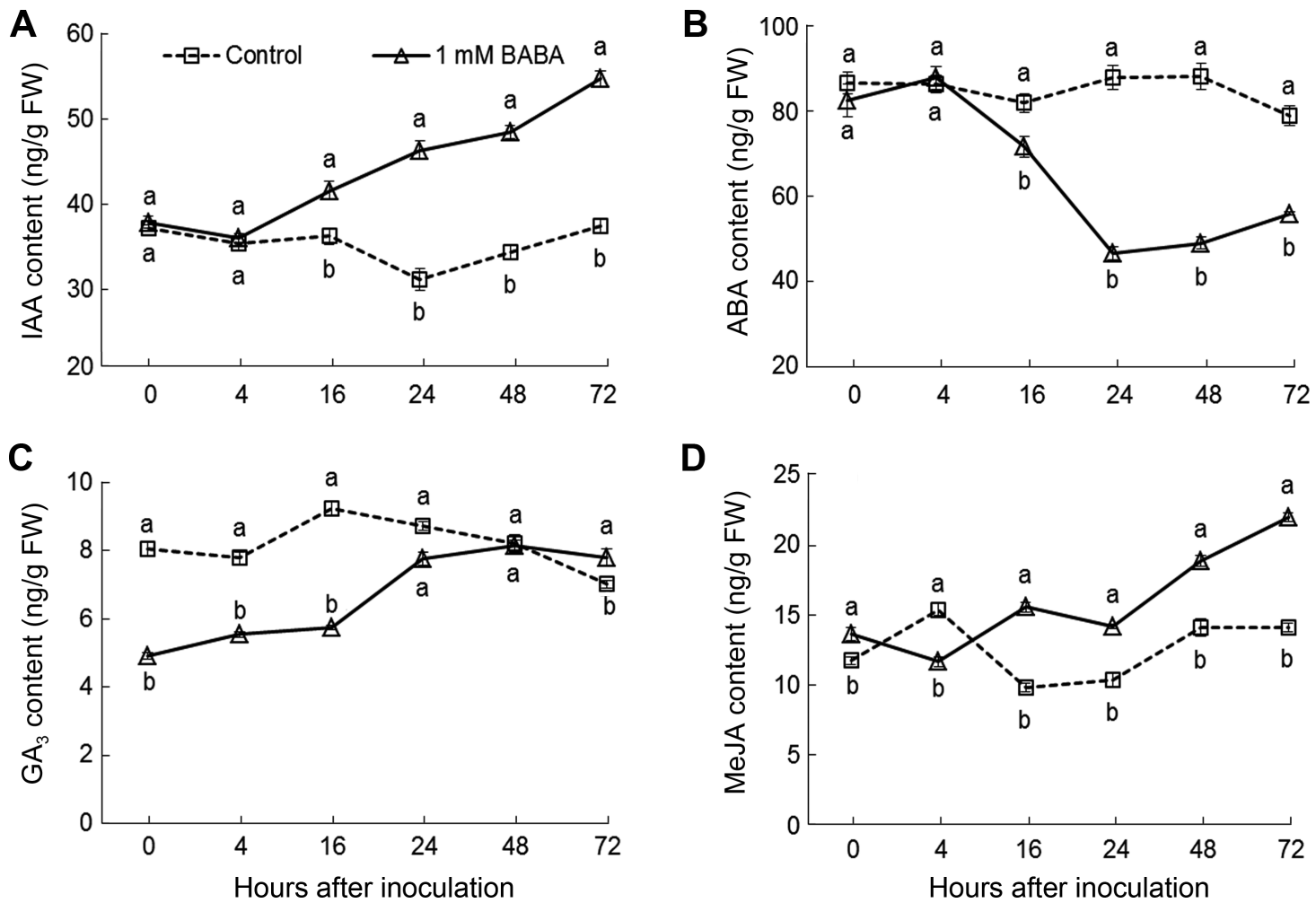

Fig. 5. Effects of $\beta$-aminobutyric acid (BABA) treatment on concentrations of plant hormones indole acetic acid (IAA) (A), abscisic acid $(\mathrm{ABA})(\mathrm{B})$, gibberellic acid $\left(\mathrm{GA}_{3}\right)(\mathrm{C})$, and methyl jasmonate (MeJA) (D). Values followed by different letters are significantly different according to Duncan's multiple range tests at $P<0.05$. Data are expressed as mean $\pm \mathrm{SD}$ of triplicate assays.

$(P<0.05)$ (Fig. 5C). BABA treatment markedly increased MeJA concentration from $4 \mathrm{~h}$ after inoculation compared to control $(P<0.05)$ (Fig. 5D).

Effects of BABA treatment on NO level. To investigate whether NO is involved in BABA-enhanced resistance to B. cinereal, NO level was measured after BABA treatment. Interestingly, plants treated with BABA alone showed a rapid increase in $\mathrm{NO}$ level, reaching a maximum at $4 \mathrm{~h}$ after BABA treatment with $3.49 \mu \mathrm{M} / \mathrm{g}$ FW. Although NO content declined slowly following the rise, it remained significantly higher than that in the control $(P<0.05)$ (Fig. 6). Moreover, compared with BABA treatment alone, the NO level in BABA + cPTIO-treated plants showed a significant reduction $(P<0.05)$ (Fig. 6). The level of NO in control showed minor fluctuations but remained at a relatively low level during the entire sampling period (Fig. 6).

\section{Effects of the combination of BABA and cPTIO on} symptom severity. To investigate the effects of $\mathrm{NO}$ in BABA-enhanced resistance to $B$. cinereal, NO specific scavenger cPTIO was used diminish NO accumulation. Compared with control, plants treated with $\mathrm{BABA}$ alone

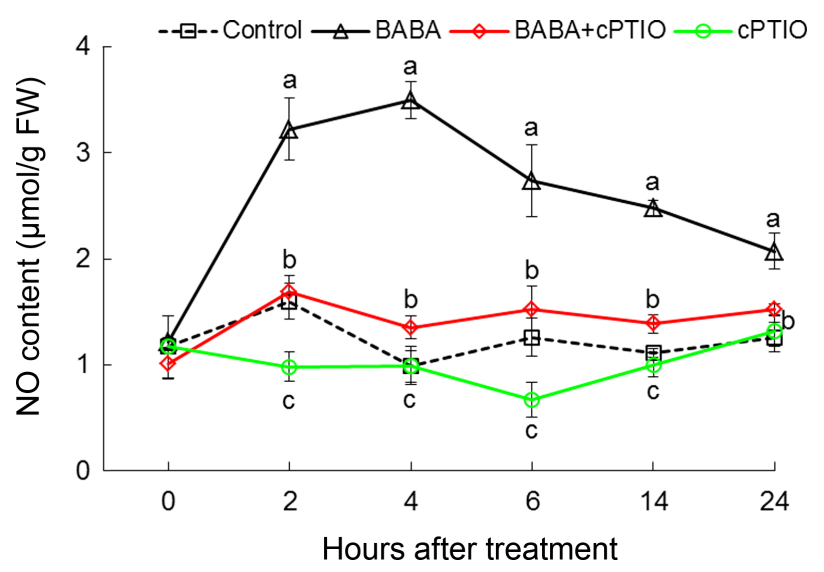

Fig. 6. Effects of $\beta$-aminobutyric acid (BABA) treatment on nitric oxide (NO) level in tomato plants. Plants were treated with BABA, BABA plus cPTIO, and cPTIO (water as control), respectively. Values followed by different letters are significantly different according to Duncan's multiple range tests at $P<0.05$. Data are expressed as mean $\pm \mathrm{SD}$ of triplicate assays.

exhibited significantly reduced lesion areas on days 2 and 4 after inoculation. Meanwhile, disease incidence in BABA-treated plants was also decreased on days 2 and 
Table 2. Effects of BABA treatment on disease incidence and lesion area in tomato plants

\begin{tabular}{lcccccc}
\hline \multirow{2}{*}{ Treatments } & \multicolumn{2}{c}{ Disease incidence $(\%)$} & & \multicolumn{2}{c}{ Lesion area $\left(\mathrm{cm}^{2}\right)$} \\
\cline { 2 - 3 } \cline { 5 - 6 } & After 2 days & After 4 days & & After 2 days & After 4 days \\
\hline Control & $82.00 \pm 4.12 \mathrm{a}$ & $93.40 \pm 1.14 \mathrm{a}$ & & $0.30 \pm 0.03 \mathrm{a}$ & $0.54 \pm 0.04 \mathrm{a}$ \\
BABA & $72.00 \pm 2.35 \mathrm{~b}$ & $86.00 \pm 1.00 \mathrm{~b}$ & & $0.23 \pm 0.03 \mathrm{~b}$ & $0.33 \pm 0.03 \mathrm{c}$ \\
BABA + cPTIO & $83.80 \pm 4.49 \mathrm{a}$ & $95.60 \pm 1.82 \mathrm{a}$ & & $0.28 \pm 0.04 \mathrm{ab}$ & $0.46 \pm 0.03 \mathrm{~b}$ \\
cPTIO & $85.60 \pm 3.65 \mathrm{a}$ & $93.80 \pm 1.92 \mathrm{a}$ & & $0.33 \pm 0.04 \mathrm{a}$ & $0.50 \pm 0.04 \mathrm{a}$ \\
\hline
\end{tabular}

Six-week-old plants were sprayed with $\beta$-aminobutyric acid (BABA), BABA plus cPTIO, and cPTIO (water as control), respectively. Botrytis cinerea inoculation was carried out on 2 days after spraying. Disease incidence and lesion area were measured 2 and 4 days after inoculation at $25^{\circ} \mathrm{C}$. Data are expressed as the mean $\pm \mathrm{SD}$ of triplicate assays. Means in a column followed by a different letter differ significantly at $P<0.05$ by Duncan's multiple range tests.

4 after inoculation by $12.2 \%$ and $7.9 \%$, respectively $(P<$ 0.05 ) (Table 2). However, BABA-induced resistance was weakened by cPTIO application. Compared with plants treated by $\mathrm{BABA}$ alone, treatment with $\mathrm{BABA}$ plus $\mathrm{CPTIO}$ significantly increased the disease incidence, which rose by $14.1 \%$ and $10.0 \%$ on days 2 and 4 after inoculation. Moreover, the lesion area of BABA + cPTIO-treated plants was 1.2- and 1.4-fold higher compared to plants treated with BABA alone on days 2 and 4 after inoculation $(P<0.05)$ (Table 2).

\section{Discussion}

BABA treatment reduced the symptom severity caused by $B$. cinerea. BABA is considered a positive inducer of host resistance in a wide range of plants (Cohen et al., 2016; Floryszak-Wieczorek et al., 2015; Wang et al., 2018). In Arabidopsis, BABA treatment reduces the sensitivity of plants to two distinct strains of $B$. cinerea (Zimmerli et al., 2001). In the present study, $1 \mathrm{mM}$ BABA significantly decreased the disease incidence and lesion area of tomato plants infected by $B$. cinerea (Fig. 2), implying that $1 \mathrm{mM}$ BABA applied via a foliar spray was sufficient and effective to enhance the defense response of tomato plant against $B$. cinerea $(P<0.05)$ (Fig. $2 \mathrm{~B}$ and $\mathrm{C})$. This application concentration of BABA $(1 \mathrm{mM})$ in this study was notably lower than those used in previous experiments (Jakab et al., 2001; Worrall et al., 2012), which might be due to differences in experimental condition and tomato cultivar. This result suggests that BABA treatment might be viable tool to alleviate $B$. cinerea invasion in agricultural production.

BABA treatment improved activities of defense enzymes. Plants have evolved a sophisticated system that incorporates both non-enzymatic and enzymatic mechanisms in response to various pathogens (Zheng et al., 2015). In higher plants, PAL is a pivotal enzyme of the phenylpropanoid pathway, which is considered to be a key metabolic pathway in disease resistance (Zhang and Liu, 2015). PPO is a nuclear encoded enzyme catalyzing the oxidation of phenols to $o$-quinones, and overexpressing the $P P O$ gene can enhance resistance against $P$. syringae in tomato plants (Li and Steffens, 2002; Taranto et al., 2017). GLU and $\mathrm{CHI}$, enzymes belonging to pathogenesis-related (PR) gene families, could damage the fungal cell wall via catalyzing the hydrolysis of $\beta$-1,3-glucan and chitin, respectively (Yim et al., 2014). Thus, activities of these four defense enzymes reflect the level of disease resistance against $B$. cinerea in tomato plants. In our previous reports, tomato fruits or plants less susceptible to $B$. cinerea always showed increased activities of PAL, PPO, GLU, and CHI (Zhang et al., 2018; Zheng et al., 2015). In this study, BABA-treated plants exhibited enhanced activity of defense enzymes $(P$ $<0.05$ ) (Fig. 3), which suggests that BABA might increase resistance against $B$. cinerea in tomato plants by enhancing the activity of defense enzymes.

BABA treatment increased expression of defense genes. The SA signaling pathway was proven to be involved in BABA-induced resistance (Cohen, 2002; Martínez-Aguilar et al., 2016). Pathogenesis-related genes 1 (PRl) is a representative marker gene of the SA-dependent defense signaling pathway (Jakab et al., 2001). BABA-induced resistance against Phytophthora infestans was accompanied by PR protein accumulation (Cohen et al., 1994), which is in agreement with the higher relative expression of SIPRl in this study. Non-expresser of pathogenesis-related genes 1 (NPRl) is essential to activate $P R$ gene expression (Mukhtar et al., 2009). Up-regulated transcription of SINPR1 in BABA-treated tomato plants was observed in this study, which is supported by previous results showing that functional 
NPR1 is indispensable for the established defense response to $B$. cinerea (Zimmerli et al., 2001). Furthermore, EDS1 and FAD4 encoded lipase-like proteins involved in the SA signaling pathway, and up-regulation of SIEDS1 and SlFAD4 was observed in pathogen-infected leaves (Kachroo et al., 2005). This is in concordance with the higher expressions of SIEDS1 and SlFAD4 observed in BABA-treated plants $(P<0.05)$ (Fig. 4B and D). In summary, BABA treatment significantly increased relative expression of SlPR1, SlNPR1, SlEDS1, and SlFAD4 $(P<0.05)$ (Fig. 4), which indicates that an EDS1/PAD4-dependent SA signaling defense pathway might be involved in BABAenhanced resistance against $B$. cinerea.

BABA treatment altered plant hormones levels in tomato plants. Auxin was the first identified phytohormone and is found in all land plants and several soil-dwelling microbes (Tivendale et al., 2014). BABA treatment reportedly leads to a boost of primary metabolites of tricarboxylic acid cycle and promotes IAA biosynthesis in Arabidopsis (Gamir et al., 2012), which is consistent with the increased IAA content we observed in BABA-treated plants (Fig. 5A). ABA plays a negative role in the regulation of plant defense against various biotrophic and necrotrophic pathogens (Bari and Jones, 2009). ABA-deficient tomato mutants show more resistance against $B$. cinerea (Audenaert et al., 2002), which supports the reduced ABA content in BABA-treated plants less susceptible to $\mathrm{B}$. $\mathrm{ci}$ nerea reported here (Figs. 2 and 5B). Moreover, the lower ABA level of BABA-treated plants might result from the activated EDS1/PAD4-dependent SA signaling pathway, which could reduce ABA accumulation through affecting $\mathrm{Ca}^{2+}$ signal transduction (Shigenaga and Argueso, 2016).
Furthermore, gibberellins $\left(\mathrm{GA}_{\mathrm{S}}\right)$ are a large family of tetracyclic diterpenoid hormones, and $\mathrm{GA}_{3}$ acts as a virulence factor to promote plant susceptibility during pathogen infections (Bari and Jones, 2009). This concurs with our results that decreased $\mathrm{GA}_{3}$ concentration in BABA-treated plants was accompanied by less susceptibility to $B$. cinerea (Figs. 2 and 5C). JA plays a central role in a variety of physiological processes (Ranjan et al., 2015). MeJA treatment can enhance the resistance against $B$. cinerea in tomato fruits (Zhang et al., 2011), which is consistent with the remarkably higher level of MeJA in BABA-treated plants that we observed $(P<0.05)$ (Fig. 5D). All these results indicate that plant hormones, including IAA, $\mathrm{ABA}, \mathrm{GA}_{3}$, and MeJA, are involved in BABA-induced resistance against $B$. cinerea in tomato plants.

BABA treatment enhanced NO levels in tomato plants. NO burst is considered a common reaction of plants to biotic as well as abiotic stresses (Ruan et al., 2015). Many studies showed that NO participates in the establishment of defense responses to pathogens (Floryszak-Wieczorek et al., 2012; Perchepied et al., 2010). In order to evaluate whether $\mathrm{NO}$ is involved in the regulation mechanism of BABA-induced resistance against $B$. cinerea, the NO level was measured. As shown in Fig. 6, NO accumulation in BABA-treated plants displayed a time-dependent rise and peaked at $4 \mathrm{~h}$ after treatment, which indicates that $\mathrm{NO}$ might be induced by BABA.

Role of NO in BABA-enhanced resistance against $B$. cinerea. In the present study, BABA treatment enhanced resistance against $B$. cinerea in tomato plants $(P<0.05)$ (Fig. 2), which was accompanied with a NO burst. To fur-

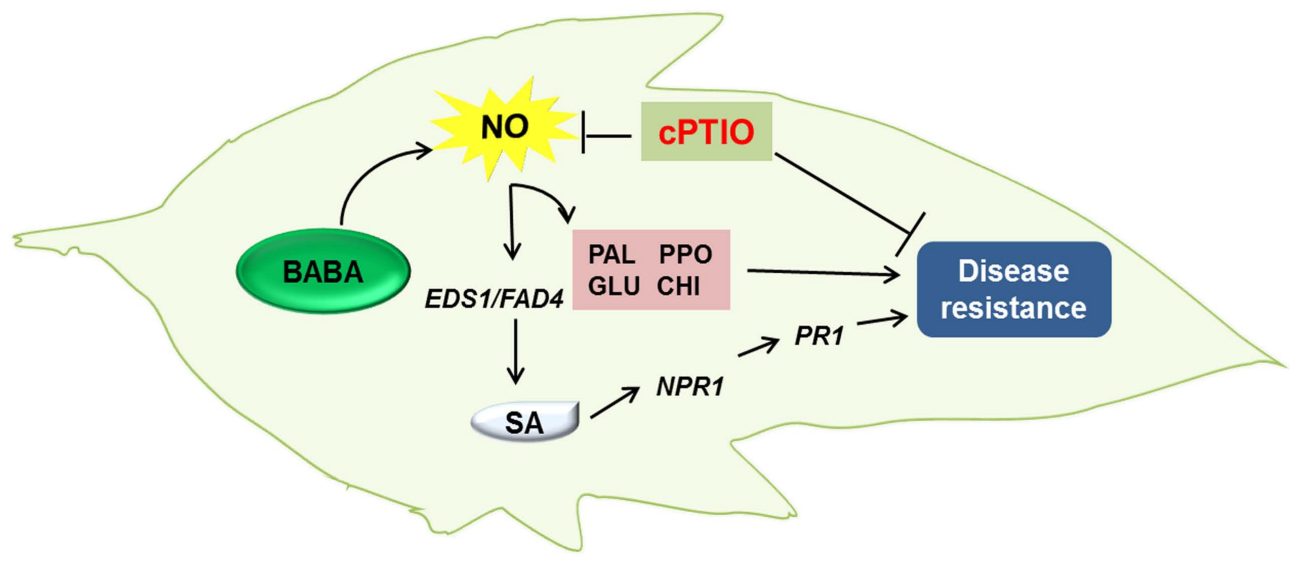

Fig. 7. Proposed model for the possible roles of nitric oxide (NO) accumulation, defense enzymes, and salicylic acid (SA)-related defense pathway in $\beta$-aminobutyric acid (BABA)-induced resistance against Botrytis cinerea in tomato plants. PAL, phenylalanine ammonialyase; PPO, polyphenol oxidase; GLU, $\beta$-1,3-glucanases; CHI, chitinase. 
ther investigate the special role of $\mathrm{NO}$ in BABA-enhanced resistance against $B$. cinerea, $\mathrm{cPTIO}$ was used to diminish NO accumulation (Wany et al., 2017). NO levels in plants treated with BABA plus cPTIO were obviously reduced compared with plants treated with BABA alone $(P<0.05)$ (Fig. 6), suggesting that BABA-triggered NO accumulation was effectively abolished by cPTIO. Additionally, the symptom severity of plants treated with BABA plus cPTIO significantly increased compared with plants treated with BABA alone $(P<0.05)$ (Table 2$)$, which implies that BABA-triggered $\mathrm{NO}$ accumulation might be crucial for protecting tomato plants against $B$. cinerea. Moreover, the BABA-triggered $\mathrm{NO}$ burst occurred before $B$. cinerea inoculation, indicating that the NO burst might be an early signal to activate defense response to $B$. cinerea (Arasimowicz-Jelonek and Floryszak-Wieczorek, 2016).

In addition, evidence has shown that $\mathrm{NO}$ acts upstream of the SA signaling pathway to regulate multiple signaling pathways (Hong et al., 2008; Pieterse et al., 2009). In Arabidopsis NO triggers a SA-dependent defense response, which leads to enhanced resistance against Pseudomonas (Kovacs et al., 2015). This is consistent with our finding that BABA-induced resistance against $B$. cinerea was accompanied by a significantly higher NO level $(P<0.05)$ (Fig. 6) and a boosted SA signaling pathway $(P<0.05)$ (Fig. 4). These results suggest that NO might act as a signaling molecule to trigger a SA-dependent defense response, which might be involved in BABA-induced resistance against $B$. cinerea. However, the interactions between the NO burst and SA signaling pathway in BABA-induced resistance against $B$. cinerea remain unclear.

Conclusion. In this study, BABA treatment enhanced resistance against $B$. cinerea in tomato plants. Moreover, BABA-induced resistance against $B$. cinerea was associated with the accumulation of NO in tomato plants. The positive role of $\mathrm{NO}$ in BABA-induced resistance was confirmed by the disease symptom. Based on these results, the possible model of BABA-induced resistance against B. cinerea in tomato plants was shown in Fig. 7. Future efforts should be focused on the regulatory mechanism of BABA induced NO biosynthesis as well as the applications of BABA in practical production. This and future studies provide useful information about the specific role of $\mathrm{NO}$ in plant induced resistance against pathogens.

\section{Acknowledgements}

This work was supported by the National Natural Science Foundation of China (NO. 31371847 and 31571893).

\section{References}

Arasimowicz-Jelonek, M. and Floryszak-Wieczorek, J. 2016. Nitric oxide in the offensive strategy of fungal and oomycete plant pathogens. Front. Plant Sci. 7:252.

Audenaert, K., De Meyer, G. B. and Höfte, M. M. 2002. Abscisic acid determines basal susceptibility of tomato to Botrytis cinerea and suppresses salicylic acid-dependent signaling mechanisms. Plant Physiol. 128:491-501.

Bari, R. and Jones, J. D. G. 2009. Role of plant hormones in plant defence responses. Plant Mol. Biol. 69:473-488.

Bengtsson, T., Weighill, D., Proux-Wéra, E., Levander, F., Resjö, S., Burra, D. D., Moushib, L. I., Hedley, P. E., Liljeroth, E., Jacobson, D., Alexandersson, E. and Andreasson, E. 2014. Proteomics and transcriptomics of the BABA-induced resistance response in potato using a novel functional annotation approach. BMC Genomics 15:315.

Chester, K. S. 1933. The problem of acquired physiological immunity in plants. Q. Rev. Biol. 8:129-154.

Cohen, Y., Niderman, T., Mosinger, E. and Fluhr, R. 1994. $\beta$-Aminobutyric acid induces the accumulation of pathogenesis-related proteins in tomato (Lycopersicon esculentum L.) plants and resistance to late blight infection caused by $P h y$ tophthora infestans. Plant Physiol. 104:59-66.

Cohen, Y. R. 2002. $\beta$-Aminobutyric acid-induced resistance against plant pathogens. Plant Dis. 86:448-457.

Cohen, Y., Vaknin, M. and Mauch-Mani, B. 2016. BABAinduced resistance: milestones along a 55-year journey. Phytoparasitica 44:513-538.

Conrath, U. 2011. Molecular aspects of defence priming. Trends Plant Sci. 16:524-531.

Crawford, N. M. 2006. Mechanisms for nitric oxide synthesis in plants. J. Exp. Bot. 57:471-478.

Del Río, L. A., Javier Corpas, F. and Barroso, J. B. 2004. Nitric oxide and nitric oxide synthase activity in plants. Phytochemistry 65:783-792.

Deng, A., Tan, W., He, S., Liu, W., Nan, T., Li, Z., Wang, B. and Li, Q. X. 2008. Monoclonal antibody-based enzyme linked immunosorbent assay for the analysis of jasmonates in plants. J. Integr. Plant Biol. 50:1046-1052.

Fan, B., Shen, L., Liu, K., Zhao, D., Yu, M. and Sheng, J. 2008. Interaction between nitric oxide and hydrogen peroxide in postharvest tomato resistance response to Rhizopus nigricans. J. Sci. Food Agric. 88:1238-1244.

Flors, V., Ton, J., Van Doorn, R., Jakab, G., García-Agustín, P. and Mauch-Mani, B. 2008. Interplay between JA, SA and ABA signalling during basal and induced resistance against Pseudomonas syringae and Alternaria brassicicola. Plant J. 54:81-92.

Floryszak-Wieczorek, J., Arasimowicz-Jelonek, M. and Abramowski, D. 2015. BABA-primed defense responses to Phytophthora infestans in the next vegetative progeny of potato. Front. Plant Sci. 6:844. 
Floryszak-Wieczorek, J., Arasimowicz-Jelonek, M., Milczarek, G., Janus, L., Pawlak-Sprada, S., Abramowski, D., Deckert, J. and Billert, H. 2012. Nitric oxide-mediated stress imprint in potato as an effect of exposure to a priming agent. Mol. PlantMicrobe Interact. 25:1469-1477.

Gamir, J., Pastor, V., Cerezo, M. and Flors, V. 2012. Identification of indole-3-carboxylic acid as mediator of priming against Plectosphaerella cucumerina. Plant Physiol. Biochem. 61:169-179.

Gill, S. S., Hasanuzzaman, M., Nahar, K., Macovei, A. and Tuteja, N. 2013. Importance of nitric oxide in cadmium stress tolerance in crop plants. Plant Physiol. Biochem. 63:254-261.

Hao, G.-P., Xing, Y. and Zhang, J.-H. 2008. Role of nitric oxide dependence on nitric oxide synthase-like activity in the water stress signaling of maize seedling. J. Integr. Plant Biol. 50:435-442.

Hong, J. K., Yun, B.-W., Kang, J.-G., Raja, M. U., Kwon, E., Sorhagen, K., Chu, C., Wang, Y. and Loake, G. J. 2008. Nitric oxide function and signalling in plant disease resistance. $J$. Exp. Bot. 59:147-154.

Jakab, G., Cottier, V., Toquin, V., Rigoli, G., Zimmerli, L., Métraux, J.-P. and Mauch-Mani, B. 2001. $\beta$-Aminobutyric acidinduced resistance in plants. Eur. J. Plant Pathol. 107:29-37.

Ji, H., Kyndt, T., He, W., Vanholme, B. and Gheysen, G. 2015. $\beta$-Aminobutyric acid-induced resistance against root-knot nematodes in rice is based on increased basal defense. Mol. Plant-Microbe Interact. 28:519-533.

Kachroo, P., Venugopal, S. C., Navarre, D. A., Lapchyk, L. and Kachroo, A. 2005. Role of salicylic acid and fatty acid desaturation pathways in ssi2-mediated signaling. Plant Physiol. 139:1717-1735.

Kovacs, I., Durner, J. and Lindermayr, C. 2015. Crosstalk between nitric oxide and glutathione is required for nonexpressor of pathogenesis-related genes 1 (NPR1)-dependent defense signaling in Arabidopsis thaliana. New Phytol. 208:860-872.

Li, L. and Steffens, J. C. 2002. Overexpression of polyphenol oxidase in transgenic tomato plants results in enhanced bacterial disease resistance. Planta 215:239-247.

Livak, K. J. and Schmittgen, T. D. 2001. Analysis of relative gene expression data using real-time quantitative PCR and the $2^{-\Delta \Delta \mathrm{CT}}$ Method. Methods 25:402-408.

Martínez-Aguilar, K., Ramírez-Carrasco, G., Hernández-Chávez, J. L., Barraza, A. and Alvarez-Venegas, R. 2016. Use of BABA and INA as activators of a primed state in the common bean (Phaseolus vulgaris L.). Front. Plant Sci. 7:653.

Mukhtar, M. S., Nishimura, M. T. and Dangl, J. 2009. NPR1 in plant defense: it's not over 'til it's turned over. Cell 137:804806.

Noorbakhsh, Z. and Taheri, P. 2016. Nitric oxide: a signaling molecule which activates cell wall-associated defense of tomato against Rhizoctonia solani. Eur. J. Plant Pathol. 144:551-568.

Perchepied, L., Balagué, C., Riou, C., Claudel-Renard, C., Rivière, N., Grezes-Besset, B. and Roby, D. 2010. Nitric oxide participates in the complex interplay of defense-related signaling pathways controlling disease resistance to Sclerotinia sclerotiorum in Arabidopsis thaliana. Mol. Plant-Microbe Interact. 23:846-860.

Pieterse, C. M. J., Leon-Reyes, A., Van der Ent, S. and Van Wees, S. C. M. 2009. Networking by small-molecule hormones in plant immunity. Nat. Chem. Biol. 5:308-316.

Piterková, J., Hofman, J., Mieslerová, B., Sedlářová, M., Luhová, L., Lebeda, A. and Petrrivalský, M. 2011. Dual role of nitric oxide in Solanum spp.-Oidium neolycopersici interactions. Environ. Exp. Bot. 74:37-44.

Ranjan, A., Vadassery, J., Patel, H. K., Pandey, A., Palaparthi, R., Mithöfer, A. and Sonti, R. V. 2015. Upregulation of jasmonate biosynthesis and jasmonate-responsive genes in rice leaves in response to a bacterial pathogen mimic. Funct. Integr. Genomics 15:363-373.

Ruan, J., Li, M., Jin, H., Sun, L., Zhu, Y., Xu, M. and Dong, J. 2015. UV-B irradiation alleviates the deterioration of coldstored mangoes by enhancing endogenous nitric oxide levels. Food Chem. 169:417-423.

Saavedra, G. M., Sanfuentes, E., Figueroa, P. M. and Figueroa, C. R. 2017. Independent preharvest applications of methyl jasmonate and chitosan elicit differential upregulation of defense-related genes with reduced incidence of gray mold decay during postharvest storage of Fragaria chiloensis fruit. Int. J. Mol. Sci. 18:1420.

Sami, F., Faizan, M., Faraz, A., Siddiqui, H., Yusuf, M. and Hayat, S. 2018. Nitric oxide-mediated integrative alterations in plant metabolism to confer abiotic stress tolerance, NO crosstalk with phytohormones and NO-mediated post translational modifications in modulating diverse plant stress. Nitric Oxide 73:22-38.

Shigenaga, A. M. and Argueso, C. T. 2016. No hormone to rule them all: interactions of plant hormones during the responses of plants to pathogens. Semin. Cell Dev. Biol. 56:174-189.

Taranto, F., Pasqualone, A., Mangini, G., Tripodi, P., Miazzi, M. M., Pavan, S. and Montemurro, C. 2017. Polyphenol oxidases in crops: biochemical, physiological and genetic aspects. Int. J. Mol. Sci. 18:377.

Thevenet, D., Pastor, V., Baccelli, I., Balmer, A., Vallat, A., Neier, R., Glauser, G. and Mauch-Mani, B. 2017. The priming molecule $\beta$-aminobutyric acid is naturally present in plants and is induced by stress. New Phytol. 213:552-559.

Tivendale, N. D., Ross, J. J. and Cohen, J. D. 2014. The shifting paradigms of auxin biosynthesis. Trends Plant Sci. 19:44-51.

Ton, J., Jakab, G., Toquin, V., Flors, V., Iavicoli, A., Maeder, M. N., Métraux, J.-P. and Mauch-Mani, B. 2005. Dissecting the beta-aminobutyric acid-induced priming phenomenon in Arabidopsis. Plant Cell 17:987-999.

Ton, J. and Mauch-Mani, B. 2004. $\beta$-amino-butyric acid-induced resistance against necrotrophic pathogens is based on ABAdependent priming for callose. Plant J. 38:119-130.

Wang, J., Cao, S., Wang, L., Wang, X., Jin, P. and Zheng, Y. 2018. Effect of $\beta$-aminobutyric acid on disease resistance against Rhizopus rot in harvested peaches. Front. Microbiol. 9:1505.

Wang, X., Xu, F., Wang, J., Jin, P. and Zheng, Y. 2013. Bacil- 
lus cereus $\mathrm{AR} 156$ induces resistance against Rhizopus rot through priming of defense responses in peach fruit. Food Chem. 136:400-406.

Wany, A., Kumari, A. and Gupta, K. J. 2017. Nitric oxide is essential for the development of aerenchyma in wheat roots under hypoxic stress. Plant Cell Environ. 40:3002-3017.

Worrall, D., Holroyd, G. H., Moore, J. P., Glowacz, M., Croft, P., Taylor, J. E., Paul, N. D. and Roberts, M. R. 2012. Treating seeds with activators of plant defence generates long-lasting priming of resistance to pests and pathogens. New Phytol. 193:770-778.

Yim, W. J., Kim, K. Y., Lee, Y. W., Sundaram, S. P., Lee, Y. and Sa, T. M. 2014. Real time expression of ACC oxidase and PR-protein genes mediated by Methylobacterium spp. in tomato plants challenged with Xanthomonas campestris pv. vesicatoria. J. Plant Physiol. 171:1064-1075.

Zhang, S., Wang, L., Zhao, R., Yu, W., Li, R., Li, Y., Sheng, J. and Shen, L. 2018. Knockout of SIMAPK3 reduced disease resistance to Botrytis cinerea in tomato plants. J. Agric. Food Chem. 66:8949-8956.

Zhang, X. and Liu, C.-J. 2015. Multifaceted regulations of gateway enzyme phenylalanine ammonia-lyase in the biosynthesis of phenylpropanoids. Mol. Plant 8:17-27.

Zhang, X., Shen, L., Li, F., Meng, D. and and Sheng, J. 2011. Methyl salicylate-induced arginine catabolism is associated with up-regulation of polyamine and nitric oxide levels and improves chilling tolerance in cherry tomato fruit. J. Agric. Food Chem. 59:9351-9357.

Zheng, Y., Hong, H., Chen, L., Li, J., Sheng, J. and Shen, L. 2014. LeMAPK1, LeMAPK2, and LeMAPK3 are associated with nitric oxide-induced defense response against Botrytis cinerea in the Lycopersicon esculentum fruit. J. Agric. Food Chem. 62:1390-1396.

Zheng, Y., Shen, L., Yu, M., Fan, B., Zhao, D., Liu, L. and Sheng, J. 2011. Nitric oxide synthase as a postharvest response in pathogen resistance of tomato fruit. Postharvest Biol. Technol. 60:38-46.

Zheng, Y., Yang, Y., Liu, C., Chen, L., Sheng, J. and Shen, L. 2015. Inhibition of SlMPK1, SlMPK2, and SlMPK3 disrupts defense signaling pathways and enhances tomato fruit susceptibility to Botrytis cinerea. J. Agric. Food Chem. 63:55095517.

Zhu, M., Meng, X., Cai, J., Li, G., Dong, T. and Li, Z. 2018. Basic leucine zipper transcription factor SlbZIP1 mediates salt and drought stress tolerance in tomato. BMC Plant Biol. 18:83.

Zimmerli, L., Métraux, J.-P. and Mauch-Mani, B. 2001. $\beta$-Aminobutyric acid-induced protection of Arabidopsis against the necrotrophic fungus Botrytis cinerea. Plant Physiol. 126:517-523. 